NASA Technical Memorandum 106293

AIAA-93-1967

\title{
Ground Testing for the No-Vent Fill of Cryogenic Tanks: Results of Tests for a 71 Cubic Foot Tank
}

David J. Chato

Lewis Research Center

Cleveland, Ohio

Prepared for the

29th Joint Propulsion Conference and Exhibit cosponsored by the AIAA, SAE, ASME, and ASEE Monterey, California, June 28-30, 1993

\section{NASก}




\title{
GROUND TESTING FOR THE NO-VENT FILL OF CRYOGENIC TANKS: RESULTS OF TESTS FOR A 71 CUBIC FOOT TANK
}

\author{
D.J. Chato* \\ National Aeronautics and Space Administration \\ Lewis Research Center \\ Cleveland, Ohio 44135
}

\begin{abstract}
NASA Lewis Research has been investigating the no-vent fill method, since it is a promising approach to transfer liquid while handling the problems of low-g venting. This paper reports the results of a test series for filling a $71 \mathrm{ft}^{3}$ tank with liquid hydrogen without venting. 22 tests were conducted, 10 with a bottom orifice as the inlet and 12 with a spray bar. Parameters investigated included inlet saturation pressures of approximately 5,15 , and 25 psia, transfer pressures of 20,30 , and 45 psia, and various starting wall temperatures. Of the tests, only the one run at the highest wall temperature ( $238 \mathrm{R}$ ) failed to fill the tank. Test results are compared to a thermodynamic equilibrium model. Overall model-data agreement was good except for the tendency of the model to overshoot during the initial wall cooldown of the higher starting wall temperature fills.
\end{abstract}

\section{$\underline{\text { INTRODUCTION }}$}

The economic benefits associated with the development of reusable, space based orbit-to-orbit transfer vehicles (STV) are frequently touted by NASA and the aerospace engineering community. One of the technical challenges in making STVs a reality is the development of a low-g cryogenic propellant resupply capability. Recent analytical and experimental accomplishments as well as planned future experimentation are leading the way in the development of this key, enabling technology.

The filling of tanks in low gravity with cryogens is challenging. To maintain a low tank pressure during a fill in a normal gravity environment, a top vent is kept open to vent the vapor generated during the fill process. If the same approach is used in a low gravity environment, the vapor may not vent, since the position of the vent opening relative to the vapor cannot be predicted. Instead of vapor, large amounts of liquid may be vented. Unbalanced torques produced by venting liquid have caused spacecraft to tumble out of control.

The no-vent fill method is being developed to handle the problems of low-g venting. A receiver tank is first cooled to remove thermal energy from the tank wall and the resultant vapor vented overboard. Then nozzles mix the incoming liquid and residual vapor in the tank maintaining a thermodynamic state which allows the tank to fill with liquid without venting. The no-vent fill transfer method has been chosen for emphasis within the technology program due to its potential applicability to a wide variety of future spacecraft. Perhaps more importantly, it will minimize required orbital operations in comparison with liquid transfer techniques requiring a controlled, local acceleration environment.

\section{* Member AIAA}

Copyright (C) 1993 by the American Institute of Aeronautics and Astronautics, Inc. No copyright is asserted in the United States under Title 17, U.S. Code. The U.S. Government has a royalty-free license to exercise all rights under the copyright claimed herein for Governmental purposes. All other rights are reserved by the copyright owner. 
NASA Lewis Research Center is pursuing an ongoing investigation of the no-vent fill process to gain practical experience that will enable the use of this technique in orbital operations. This investigation has focused on both the development of analytical models for simulating the process in conceptual designs and the practical demonstration of the method in an extensive ground test program. References 1 and 2 documented tests with a large $\left(175 \mathrm{ft}^{3}\right)$ tank at NASA/LeRC's K-Site facility. These tests demonstrated the impact of varying critical input parameters, such as the liquid inlet mass flow rate and the initial tank wall temperature, on the no-vent fill process. Although due to the nature of the test setup liquid inlet temperature could not be parametrically investigated, run to run variations in inlet temperature seemed to have significant effects on the final fill pressure. A new test series was devised to investigate the effects of parametrically varying liquid inlet temperature. The new tests also provided an opportunity to investigate a different tank size with two new inlet systems.

This paper will report the finding of that new test series to investigate no-vent fill transfer technology. This series was conducted at the LeRC Plum Brook Station Cryogenic Propellant Research Facility( also known as K-site) in 1992. Tests consisted of the no-vent fill of an aluminum tank of lightweight construction, with $71 \mathrm{ft}^{3}$ internal volume. Fill tests were conducted over a broad range of inlet temperatures and transfer heads. Two injection techniques were tested: a spray bar and a bottom mounted orifice plate. Liquid hydrogen was used as the test fluid because previous work has shown it to be one of the most difficult cryogens to transfer. Hydrogen's use as a propellant and fuel cell reactant make it a commonly required cryogen as well.

The NVEQU model will be used to analyze the test results. This computer model was developed from previous test results ${ }^{2}$. The NVEQU code assumes that in a well mixed tank the no-vent fill will proceed at thermodynamic equilibrium. As a thermodynamic equilibrium model, NVEQU represents a best case fill; deviation from it indicates thermodynamic inefficiency. NVEQU allows comparisons between tests with highly differing conditions by showing how each test is affected by the thermodynamics of the process.

\section{ANALYTICAL MODELS}

The analytical models of the no-vent fill process being developed at LeRC are to evolve into predictive design tools. The models should allow the maximum pressure of the receiver tank to be predicted with reasonable accuracy ( $\pm 10 \%$ ) based on a minimum set of inputs. The models are intended to allow parametric tradeoff studies of the no-vent fill process to be performed. Tradeoff studies could examine the receiver tank maximum pressure and therefore the tank weight for different inlet parameters versus the cost and operations required to achieve the inlet conditions.

Reference 2 suggests that a thermodynamic equilibrium model is adequate to achieve these goals. Such a model was formulated in reference 2 as the NVEQU computer code. The primary assumptions incorporated in the model are: no liquid accumulation takes place prior to the tank wall being chilled to the temperature of the incoming liquid; and once liquid has started to accumulate, the liquid and vapor are in thermodynamic equilibrium. The model performs an energy balance on the tank and its fluid contents for a series of explicit time steps. Starting with the specified initial conditions; e.g. liquid inlet temperature, liquid inlet mass flow rate, tank pressure, tank wall temperature, tank mass to volume ratio, tank wall material specific heat (from reference 3); the model calculates the total fluid mass and the internal energy of the tank contents. The fluid density and enthalpy are calculated by the 
GASP program ${ }^{4}$ based on the current tank pressure. The model then iterates the tank pressure until the fluid qualities based on the density and enthalpy converge. The requisite parameters are then updated and the program proceeds to the next time step. This process continues until the desired volumetric fill level is attained, or the maximum allowable tank pressure is exceeded (currently $60 \mathrm{psia}$ ), or the program time limit is reached.

\section{EXPERIMENT DESCRIPTION}

\section{Facilities}

The no-vent fill tests were conducted at the LeRC Plum Brook Station Cryogenic Propellant Tank Facility (also known as K-Site). This facility combines a capability for safely handling liquid hydrogen with the vacuum required for multilayer insulation systems. A cryoshroud was installed inside the chamber to provide a uniform heat transfer environment. During the tests it was filled with liquid nitrogen to provide a uniform $160 \mathrm{R}$ $\pm 10 \mathrm{R}$ radiant environment for the test tank. The shroud and the chamber entry (along with a liquid hydrogen cold guard not used in this test series) are shown in figure 1.

\section{Experimental Hardware}

\section{Existing NASA LeRC hardware was} reconfigured to provide the test bed for this test series. Previous testing ${ }^{2}$ led for a desire to obtain better control over liquid inlet temperature, therefore a two tank test arrangement was implemented. The $175 \mathrm{ft}^{3}$ of reference 2 is used as a supply tank enabling the liquid condition to be controlled prior to transfer to the $71 \mathrm{ft}^{3}$ receiver tank. This configuration is shown being lowered into the cryoshroud in figure 2 . Figure 3 shows a schematic of the plumbing within the cryoshroud.
Liquid Supply The large $175 \mathrm{ft}^{3}$ tank of references 1 and 2 is used to precondition the liquid to the desired temperature. A vent to the burn stack was used to saturate the hydrogen at atmospheric pressure. A vacuum pumping system on the tank vent enables the tank to be saturated below atmospheric pressure. A regulator on the vent was used to saturate the liquid at above atmospheric. On some runs hydrogen gas was bubbled through the tank to accelerate the saturation process. An active pressure control system for the large tank maintains it at a constant pressure as liquid is transferred from it to the smaller tank during the no-vent-fill test. These systems allowed for complete control of the transfer head available for the fill process.

Test Tank The test tank selected is ellipsoidal with a 69.3 inch major diameter and a 1.41-to-1 majorto-minor axis ratio. The tank is made of 2219 aluminum chemically milled to a nominal thickness of 0.065 inches. Thicker sections exist where they were required for manufacturing (mainly weld lands). There is 0.95 inch thick by 28.35 inch diameter access flange on the top. The tank has a mass of $243 \mathrm{lb}_{\mathrm{m}}$, and the tank's volume is $71 \mathrm{ft}^{3}$, yielding a mass-to-volume ratio of $3.41 \mathrm{lb}_{\mathrm{m}} / \mathrm{ft}^{3}$. Prior to the start of testing the tank was requalified by pneumatic test for a maximum operating pressure of 50 psia. Twelve fiberglass epoxy struts support the tank in the support structure. Figure 4 shows the test tank installed in its support structure.

Spray Systems Current concepts ${ }^{4.5}$ of no-vent fill systems for low-g applications use one or more pressure atomizing spray nozzles to inject the liquid inflow. This test series explores the possibility of using a simpler system constructed with drilled holes. One system has a plate with a single sharp edge orifice $3 / 8^{\prime \prime}$ in diameter mounted near the bottom of the tank. This will fill the tank with a jet of liquid which becomes submerged soon after liquid begins to accumulate in the tank. The other system uses a vertically mounted tube capped at the 
end and drilled with small holes (0.0469 inch diameter). The holes were drilled in 12 locations evenly spaced along the tube. 4 holes were drilled at each location for a total of 48 holes. Every set of holes was shifted by $45^{\circ}$ from the previous row to provide more even wall coverage. The top row is set 5 inches down from the tank lid so that it does not impinge on the lid or tank flange ring. The flow capacities of each system were sized to have approximately the same flow rate for the same inlet pressure (roughly $1000 \mathrm{lbm} / \mathrm{hr}$ ) hydrogen at a pressure drop of 10 psid. Figure 5 shows a cutaway of the test tank with the two systems installed. Figure 6 shows a close up of the spray bar and tank internal instrumentation mounted from the tank lid.

\section{$\underline{\text { Instrumentation }}$}

Instrumentation for lines external to the test tank are shown on the Fig. 3 schematic. Instrumentation internal to the tank and on the tank wall is shown in Fig. 7.

Flowmeters Turbine flow meters are located at the inlet to each spray system. The range of the turbine meters is from 0.6 to $60 \mathrm{gpm}$ with an accuracy of $\pm 1 / 2 \%$ of the reading.

Pressure All pressure transducers are mounted outside the vacuum chamber and connected to the measurement taps by $1 / 4$ inch or $3 / 8$ inch stainless steel tubes. A 0-50 psia and a 0-100 psia transducer measure tank pressure from a tap in the tank lid. Accuracy for the pressure transducers is estimated at $\pm 1 / 2 \%$ full scale.

Tank Internal Instrumentation Internal instrumentation consists of a capacitance level sensor and a rake of temperature and point level sensors. Stainless steel was selected as the material for internal instrument support due to its low thermal conductivity at liquid hydrogen temperatures relative to other metals. The capacitance probe measures liquid fill heights by measuring the change in capacitance of two concentric stainless steel tubes as the annular space between them fills with liquid hydrogen. Changes in the dielectric constant of hydrogen with pressure prevent the accuracy of the probe from being better than $\pm 1 \%$ full scale. Twelve silicon diode temperature sensors are installed on the rake as shown in Fig. 6. To thermally isolate these sensors they are mounted on G10 micarta cards. Accuracy of these diodes is $\pm 0.9 \mathrm{R}$ below $180 \mathrm{R}$ and $1 \%$ of reading above $180 R$.

External Temperatures Silicon diode temperature sensors are used to measure temperature on the plumbing and tank wall. Two such sensors are located just downstream of the turbine flow meters, two are downstream of the spray system inlet valves, and two more on each spray system inlet pipe at $1 / 2^{\prime \prime}$ and $31 / 2^{\prime \prime}$ from where the pipe enters the tank. 22 silicon diodes are mounted at various places on the tank wall, three are on the tank drain line, and two are on the tank vent. Accuracy of these sensors are the same as the internal sensors with the exception that the data system prevents the external sensors from reading less than $29.3 \mathrm{R}$. Facility systems are instrumented with a variety of PRTs, Type E, and Type $\mathrm{K}$ thermocouples selected for the predicted temperature ranges and required accuracy.

\section{TEST PROCEDURE}

The generic test procedure followed for all of the tests is outlined below.

Initial Conditions:

-Vacuum $<10^{-5}$ Torr

-Tank filled with $\mathrm{GH}_{2}$

-Cryoshroud filled and operating at $160 \mathrm{R}$ 
Detailed Procedure:

1. Saturate supply at desired test inlet temperature

2. Cool the receiver tank wall via brief inflows

followed by vacuum pump-out to desired starting wall temperature

3. Set supply tank pressurization system to ramp and maintain desired transfer head

4. Open the valve to the desired spray system

(Valve opening will trigger data recording)

5. Terminate fill when tank level reaches $95 \%$ or tank pressure exceeds transfer head

6. Hold for $1 / 2$ hour to verify system integrity

7. Terminate recording and begin to set up for next test

\section{RESULTS}

Test results are summarized in table 1. A total of 22 no-vent fills were completed. Test identifiers were assigned on the basis of the first record number assigned by the data acquisition system at the start of the test. Saturation temperatures for the tests were selected to correspond to saturation pressures of 5,15 , and 25 psia. Transfer heads of 20,30 and 45 psia were used. All combinations of these parameters were performed except for 20 psia transfer head with 25 psia saturation for each system with the wall cooled to near liquid hydrogen temperature (8 runs apiece for a total of 16 tests). The remaining tests were run at elevated initial wall temperature (4 with the spray bar and 2 with the orifice) to determine its effect. Only the spray bar test run at the highest wall temperature (test 330) failed to fill the tank. This failed because the initial wall cooldown produced a pressure transient which exceeded the supply pressure. Once back-flow became apparent the test was terminated (less than a minute into the run). The test shows no evidence of liquid accumulated in the receiver tank. Test results are quite similar to those of reference 2 . The most notable difference between the comparable runs in the new and previous test series is a faster fill due to smaller tank size.

\section{$\underline{\text { Spray Bar Tests }}$}

Figure 8,9 , and 10 plot the receiver tank pressure from the test results and analytical model. Runs are segregated by starting wall temperature into three sets, cold wall runs where the starting wall temperature is below $40 \mathrm{R}$, moderate wall temperature runs where the wall temperature is above $40 \mathrm{R}$ but below $100 \mathrm{R}$, and elevated wall temperature runs where the wall temperature is above $100 \mathrm{R}$.

The principle determining factor of final pressure seems to be inlet temperature. The final pressure and the liquid saturation pressure, determined from inlet temperature, are close for all runs. All successful elevated wall temperature runs produce an initial pressure peak but collapse back to near saturation by the end of the fill process. As discussed previously run 330 produced a pressure spike which stopped the fill entirely. Agreement between model and experiment is good with the exception of the initial wall cooldown of the elevated temperature runs. Even in the elevated temperature runs final conditions from the model and data are in good agreement. Note also the profound effect inlet temperature has on final fill pressure. All runs conclude at pressures quite close to the inlet saturation pressure. An anomaly of the spray bar runs is a small pressure fluctuation believed to result from submerging a row of holes. This anomaly was observed in previous spray bar tests ${ }^{7}$ also.

\section{Bottom Orifice Tests}

The bottom orifice fills are shown in figures 11, 12, and 13. Again these fills are separated into cold,moderate and elevated wall temperature runs. These tests demonstrated the same model agreement as the previous spray bar runs. The elevated temperature orifice produce higher initial pressures and peak sooner than the spray bar runs at the same 
conditions. The reasons for this will be discussed further below. Also, unlike the spray bar tests, the orifice do not exhibit small fluctuations in tank pressure as the tank fills.

\section{Temperature Profiles}

Figure 14 shows the temperature history for the spray bar fill 332. Figure 15 shows temperature history for bottom orifice fill 334. These runs are the highest starting temperature runs of each system and are quite well matched in test parameters. The temperature histories show the key features typical of all the test runs. For all tests internal temperatures come to equilibrium quite quickly. Differences between maximum and minimum internal temperatures are barely discernable in the figures. Also of interest is the drop of the internal temperature below the inlet temperature indicating the possibility of flashing flow for the time period for which this condition holds. The wall temperature transients are indicative of the general trends of the test data even though most tests cool faster because of lower starting temperatures. Some parts of the tank cool quite quickly as seen by the minimum wall temperature. In the orifice fill the rest of the tank also cools reasonably fast with the entire tank dropping to close to uniform temperature after a couple of minutes. In the spray bar fill the hottest portions of the tank cool much slower taking almost 9 minutes to fully cool. Note that in both figures once the walls have cooled, temperatures are quite uniform confirming the assumption of thermodynamic equilibrium in the model.

To further investigate the cooling process, wall cooldown transients for the first 0.7 minutes are plotted as a function of location in figures 16 and 17 for spray bar fill 332 and bottom orifice fill 334 respectively. The spray bar cooldown is very similar to the bottom orifice cooldown with one exception, lid temperature of the tank represented by the top two sensors. Non-uniformity in the cooling rate at locations other than the lid is mostly due to thickening of the tank near welds such as the tank middle girth weld. All areas besides the lid are fully cooled within the 0.7 minutes shown. The bottom orifice has cooled the lid over $60 \mathrm{R}$ by 0.7 minutes whereas the spray bar has cooled the lid by less than $10 \mathrm{R}$. The spray bar by design does not impinge on the tank lid therefore the lid cools slowly. Conversely in the orifice fill the lid temperature drops faster suggesting that flow enters with sufficient velocity to impact the lid directly. But in both cases the lid cools much slower than the rest of the tank. Since the lid represents about $25 \%$ of the total tank mass, this slow lid cooling is believed to be the reason why the actual test data does not follow the rapid pressure rise rate predicted by the thermodynamic model.

\section{CONCLUSIONS}

Based on the work described herein and the ongoing work at NASA/LeRC, it appears that onorbit refueling spacecraft is feasible. No-vent fills have been performed in a normal gravity environment with two different liquid injection configurations. Both injection configurations induced sufficient interaction between the liquid and vapor phases in the receiver tank to promote condensation of the ullage; thereby, maintaining the receiver tank pressures at reasonable levels.

A total of 22 tests were completed. Of the 22 tests all but one filled the tank with more than $90 \%$ liquid volume. The test which failed was run at an elevated wall temperature. This created a rapid pressure rise at the start of the fill, which then stopped the transfer due to lack of pressure head. Of the parameters investigated the strongest influence was saturation temperature. All successful fills ended at pressures near the saturation pressure of the incoming liquid. Wall temperature strongly affects the initial pressure transients but the successful fills dropped back to near saturation at 
the end of the test. Few differences are seen between the spray bar and orifice fills, the most profound is the difference in cooldown transients. Whereas the spray bar does not impinge the lid, the data shows that for the orifice fills the lid temperature drops quite quickly suggesting that flow enters with sufficient velocity to impact the lid directly.

Work is continuing on developing analytical models of the no-vent fill process, however the ground work has been laid. A model that assumes the tank contents are at thermodynamic equilibrium during the fill process predicts the test results for both of the tested inlet configurations with good accuracy. The equilibrium model results are independent of the tank geometry and the liquid inlet configuration. Thus the results obtained with this model form a basis for comparing test results obtained for different test conditions and configurations.

The repeated success of no-vent fill tests on the ground show that, at least in normal gravity, adequate mixing can be obtained with many different injection techniques. Whether this is true in a low-g environment seems likely but is not yet proven. In order to continue the development and eventual verification and validation of the analytical models, data for no-vent fills in a low-g environment will have to be obtained.

\section{REFERENCES}

1) Chàto, D.J., "Ground Testing on the Nonvented Fill Method of Orbital Propellant Transfer: Results of Initial Test Series," NASA Technical Memorandum 104444, June 1991.

2) Taylor, W. J. and Chato, D. J. "Comparing the Results of an Analytical Model of the No-Vent Fill Process with No-Vent Fill Test Results for a $4.96 \mathrm{~m}^{3}\left(175 \mathrm{ft}^{3}\right)$ Tank," AIAA-92-3078, July 1992
3) Hendricks, R.C., Brown, A.K., and Peller, I.C, "GASP - A Computer Program for Calculating the Thermodynamic and Transport Properties for Ten Fluids: Parahydrogen, Helium, Neon, Methane, Nitrogen, Carbon Monoxide, Oxygen, Fluorine, Argon, and Carbon Dioxide," NASA Technical Note D-7808, February 1975.

4) Touloukian, Y.S, "Recommended Values of the Thermophysical Properties of Eight Alloys, Major Constituents and Their Oxides," Thermophysical Properties Research Center, Purdue University, February 1966.

5) Merino, F., Risberg, J.A., and Hill, M., "Orbital Refill of Propulsion Vehicle Tankage," NASA CR-159722, 1978.

6) Chato, D. J., "Analysis of the Nonvented Fill of a 4.96-Cubic-Meter Lightweight Liquid Hydrogen Tank," NASA Technical Memorandum 102039, August 1989.

7) Moran, M. E. and Nyland, T. W., "Hydrogen No-Vent Fill Testing Using Spray Nozzle and Spray Bar Liquid Injection," AIAA 923063, July 1992. 


\begin{tabular}{|c|c|c|c|c|c|}
\hline $\begin{array}{l}\text { Test } \\
\text { ID }\end{array}$ & $\begin{array}{l}\text { Initial Wall } \\
\text { Temp. (R) }\end{array}$ & $\begin{array}{l}\text { Liquid Inlet } \\
\text { Temp. (R) }\end{array}$ & $\begin{array}{l}\text { Inlet Mass Flowrate } \\
\qquad(\mathrm{lbm} / \mathrm{hr})\end{array}$ & $\begin{array}{l}\text { Final Pressure } \\
\text { (psia) }\end{array}$ & $\begin{array}{l}\text { Final Fill } \\
\text { Percentage }\end{array}$ \\
\hline \multicolumn{6}{|c|}{ Spray Bar Fills } \\
\hline 286 & 32.7 & 37.0 & 630 & 20.8 & 96 \\
\hline 291 & 46.0 & 31.1 & 1047 & 5.7 & 95 \\
\hline 298 & 31.7 & 37.2 & 998 & 18.0 & 97 \\
\hline 299 & 45.0 & 37.2 & 1349 & 17.7 & 96 \\
\hline 311 & 38.1 & 31.1 & 1228 & 5.6 & 94 \\
\hline 324 & 155.5 & 37.0 & 877 & 29.7 & 97 \\
\hline 326 & 151.3 & 31.2 & 1087 & 8.3 & 94 \\
\hline 330 & 232.3 & 31.4 & 804 & 33.3 & 0 \\
\hline 332 & 178.8 & 31.3 & 1017 & 10.5 & 95 \\
\hline 337 & 37.5 & 38.9 & 879 & 27.1 & 97 \\
\hline 339 & 33.5 & 39.2 & 1256 & 29.8 & 97 \\
\hline 340 & 51.8 & 31.0 & 1561 & 5.8 & 92 \\
\hline \multicolumn{6}{|c|}{ Bottom Orifice Fills } \\
\hline 283 & 56.4 & 37.4 & 790 & 19.9 & 97 \\
\hline 287 & 29.3 & 30.9 & 1385 & 5.4 & 96 \\
\hline 297 & 58.4 & 37.4 & 1380 & 16.7 & 96 \\
\hline 300 & 29.9 & 37.2 & 1747 & 16.8 & 96 \\
\hline 309 & 29.3 & 31.0 & 1724 & 5.6 & 93 \\
\hline 321 & 147.6 & 37.0 & 1126 & 20.8 & 96 \\
\hline 328 & 152.5 & 30.8 & 1652 & 8.0 & 93 \\
\hline 334 & 173.9 & 30.8 & 1518 & 9.4 & 94 \\
\hline 336 & 41.0 & 38.9 & 1198 & 22.3 & 96 \\
\hline 338 & 29.6 & 39.2 & 1735 & 23.0 & 97 \\
\hline
\end{tabular}

Table 1 Run Summary 


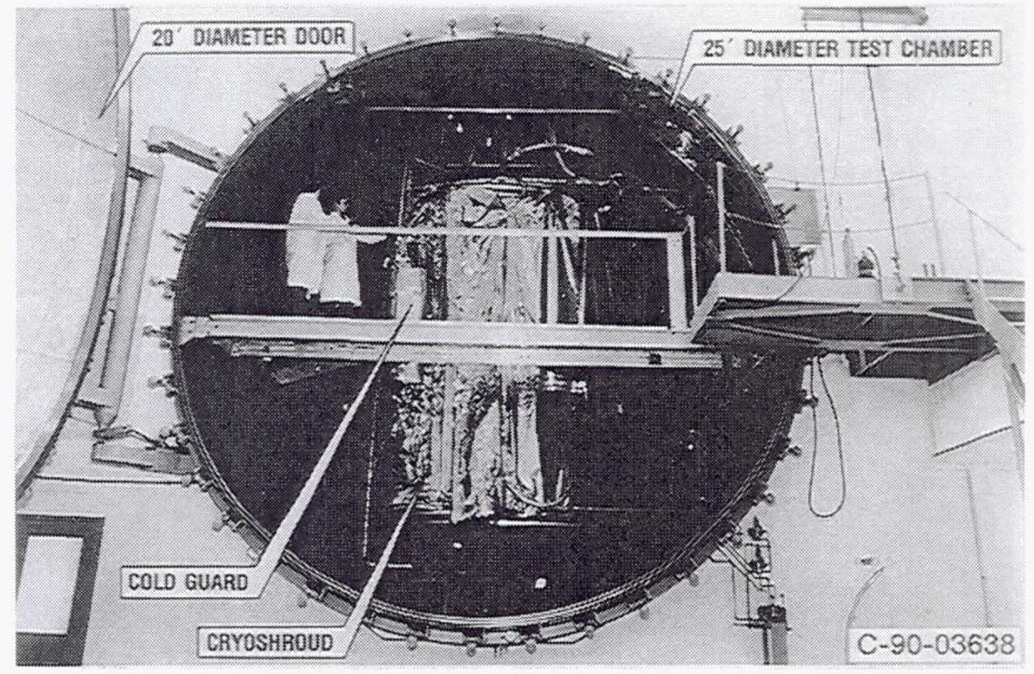

Figure 1.-K-site test facility view inside chamber with cryoshroud in place.

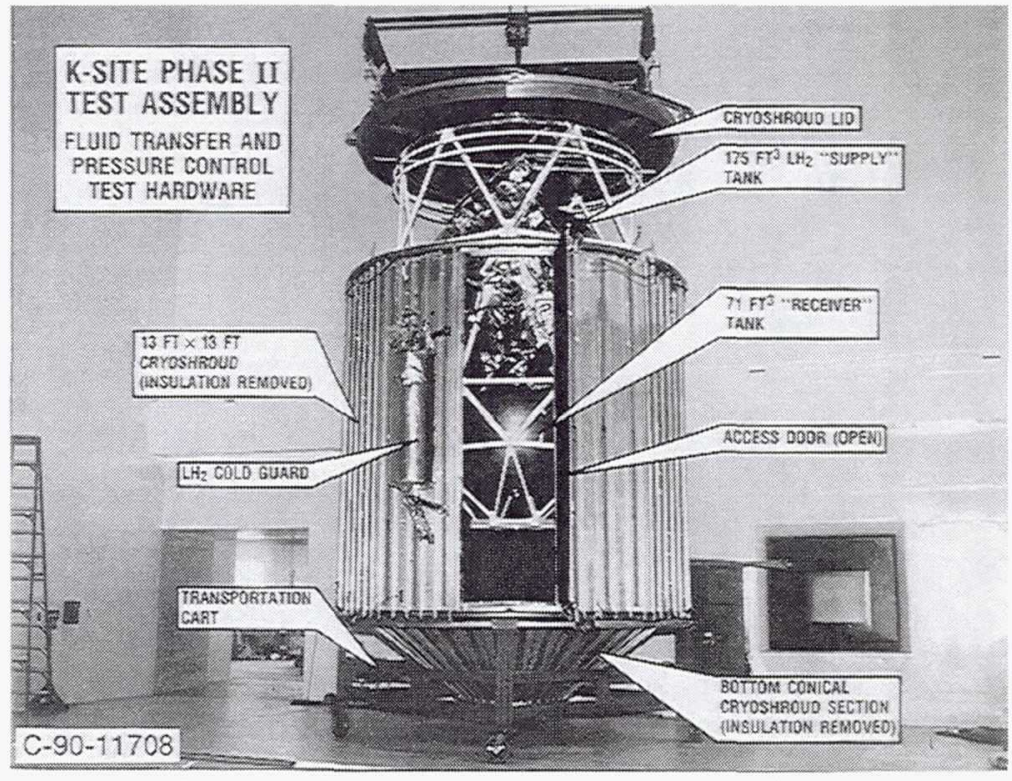

Figure 2.-Test tanks being lowered into cryoshroud. 


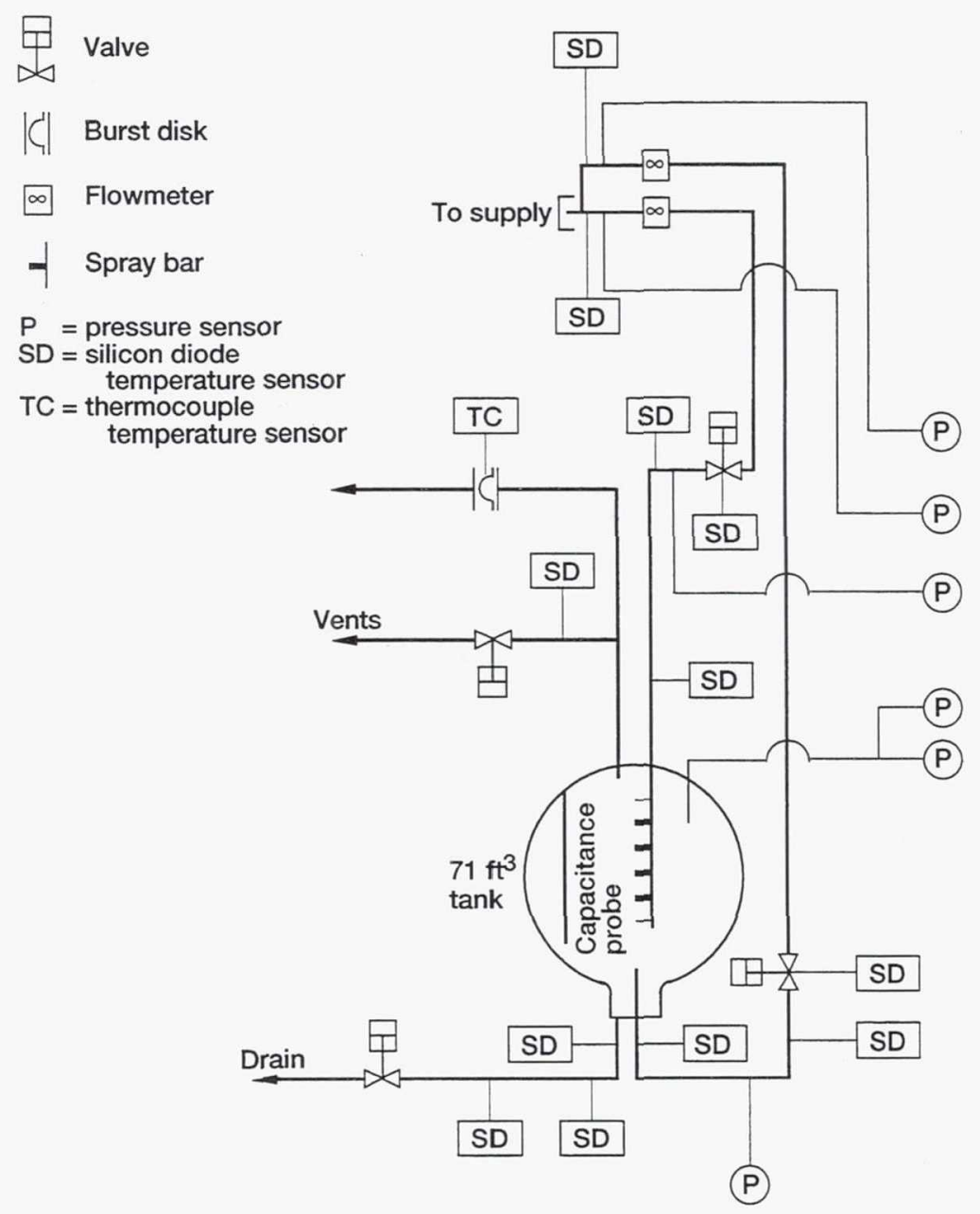

Figure 3.-Receiver tank flow schematic.

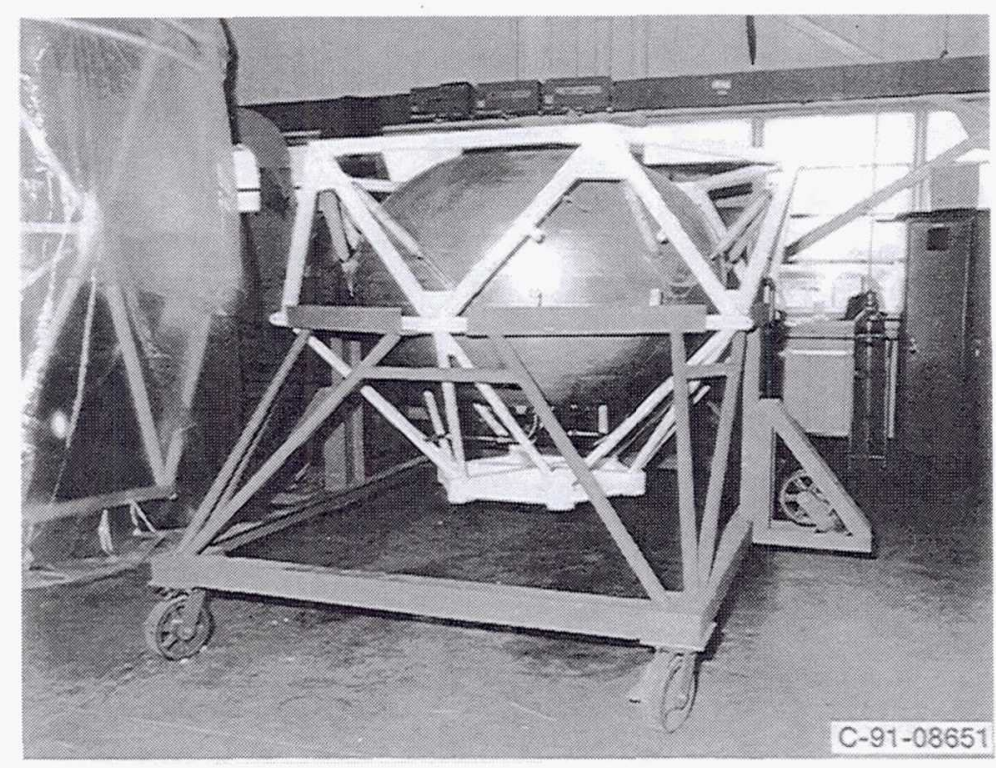

Figure 4.-Receiver tank installed in support structure. 


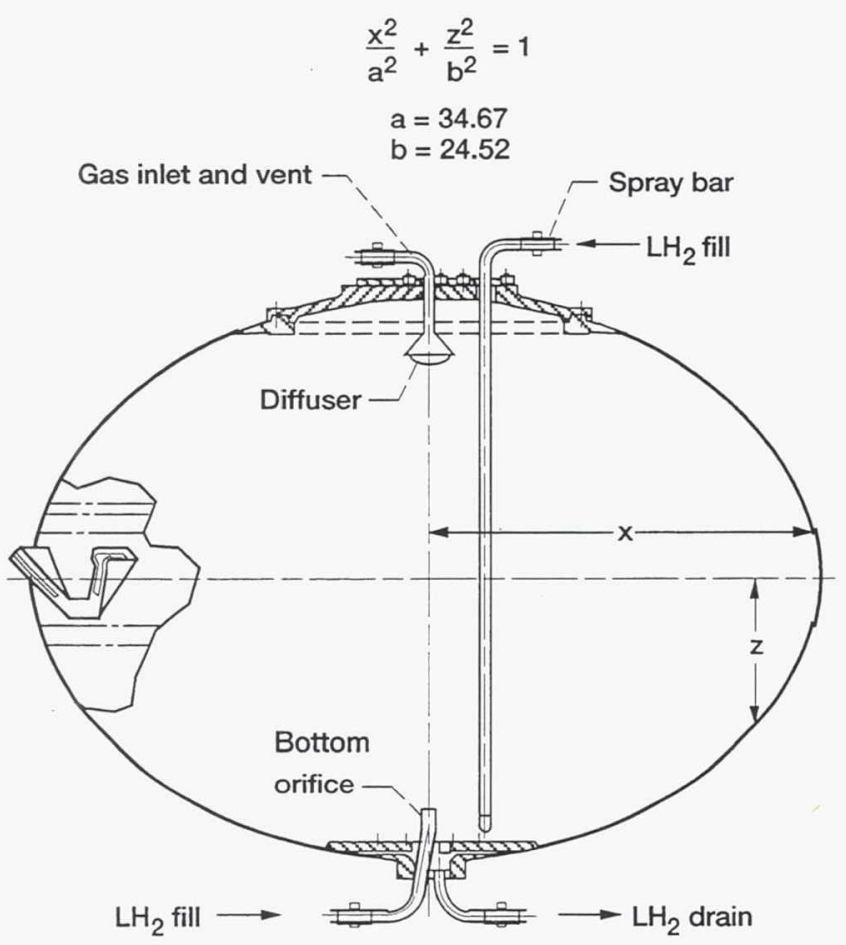

Figure 5.-Receiver tank cutaway showing spray bar and bottom orifice locations

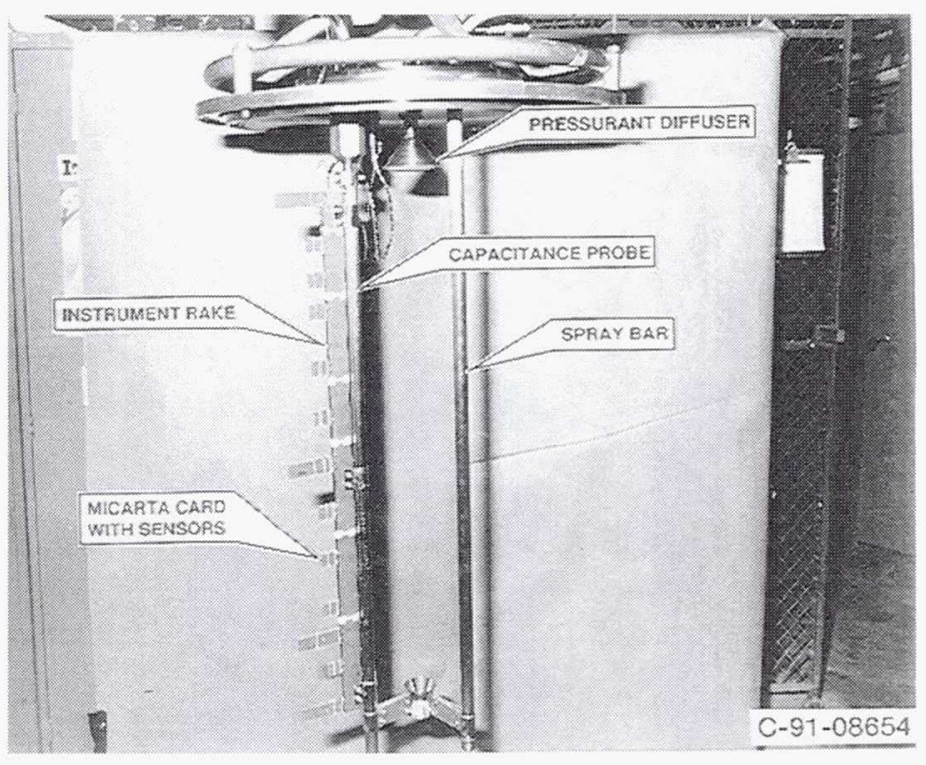

Figure 6.-Spray bar and instrumentation mounted off tank lid.

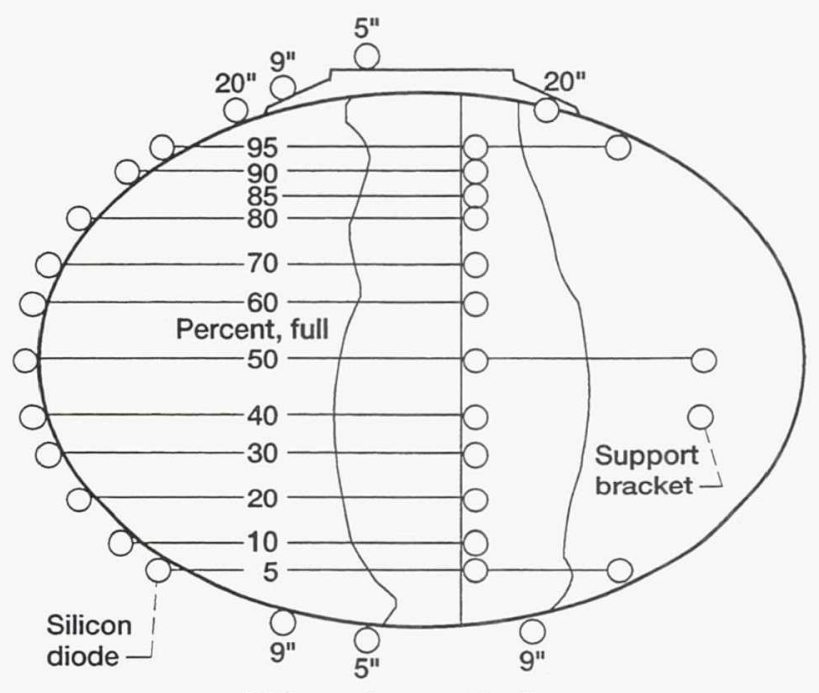

Distance from center line

Figure 7.-Wall and internal instrument locations.

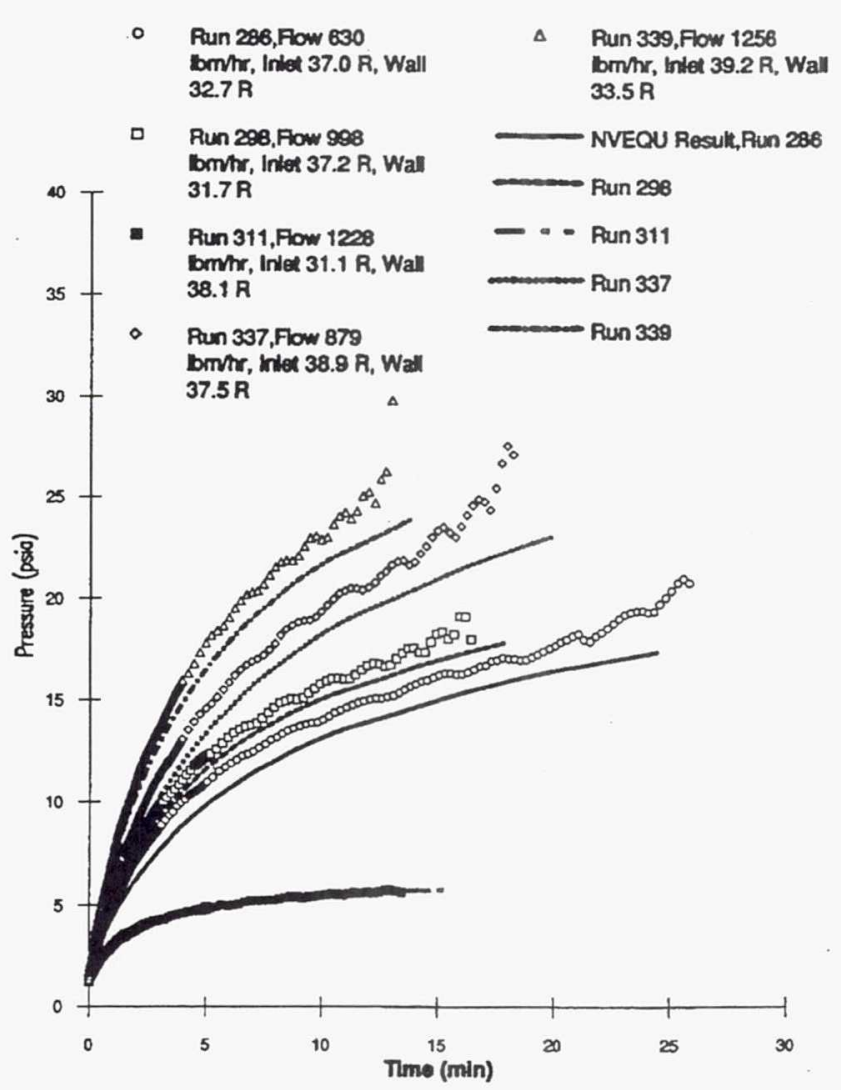

Figure 8.-Spray bar fill pressure history and analysis results runs with starting wall temperatures less than $40 \mathrm{R}$. 


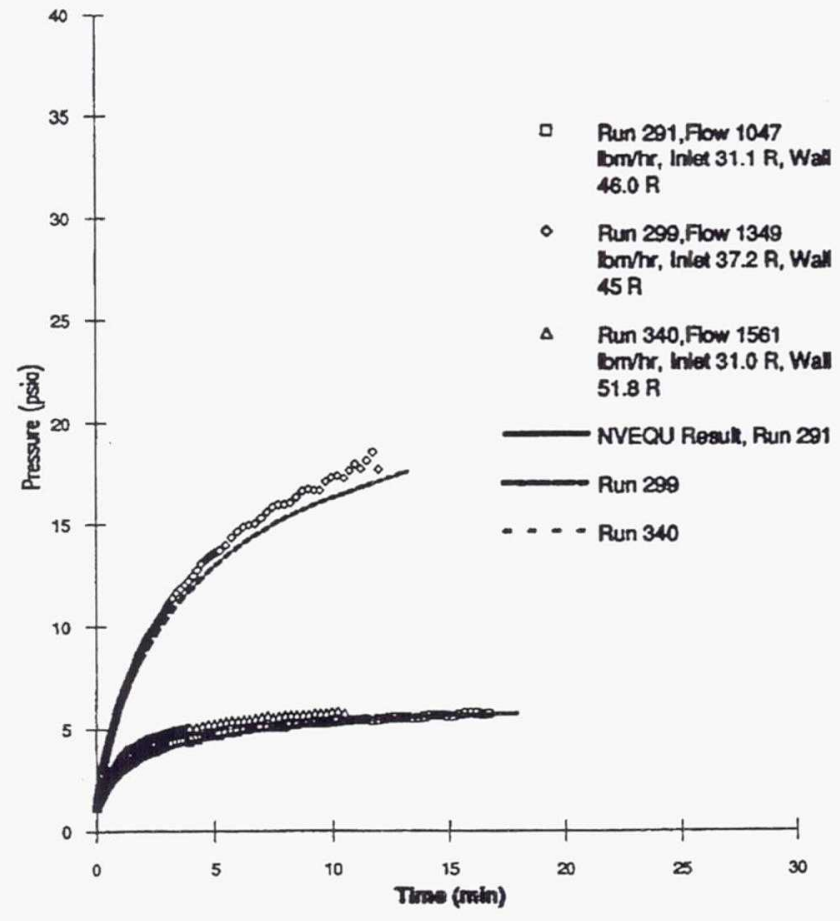

Figure 9.-Spray bar fill pressure history and analysis results runs with starting wall temperatures more than $40 R$ but less than $100 \mathrm{R}$.

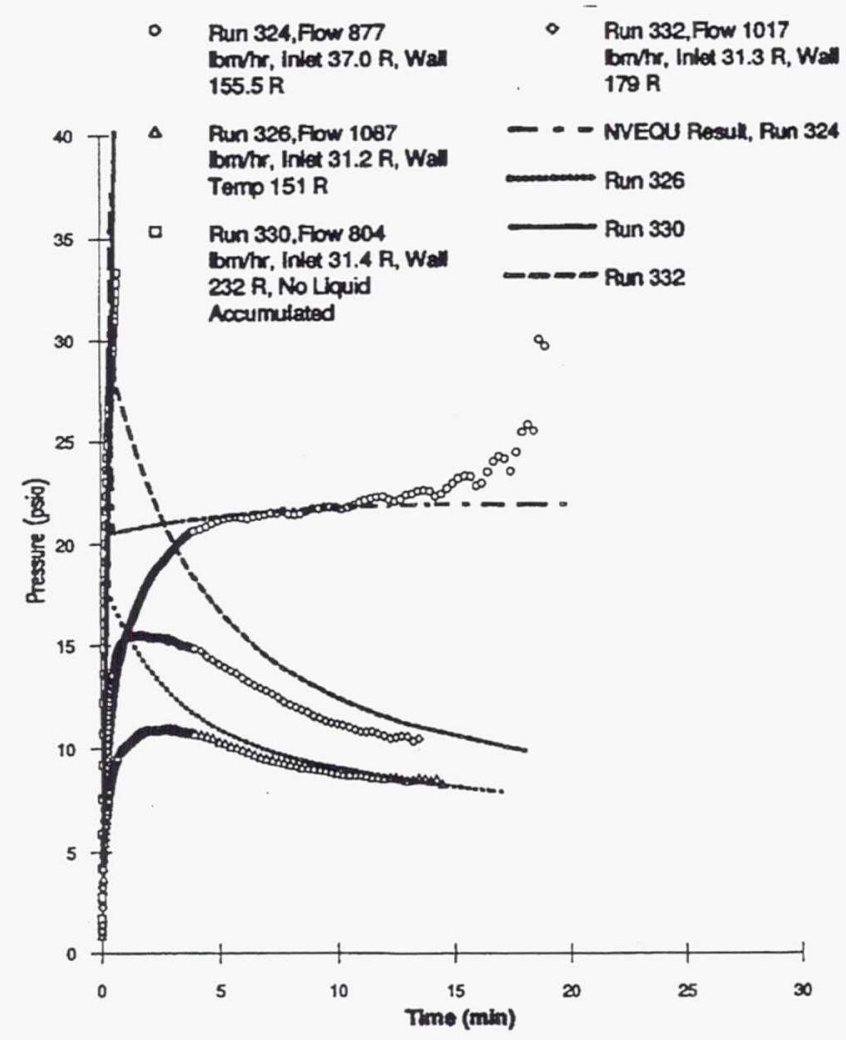

Figure 10.-Spray bar fill pressure history and analysis results runs with starting wall temperatures more than $100 \mathrm{R}$.

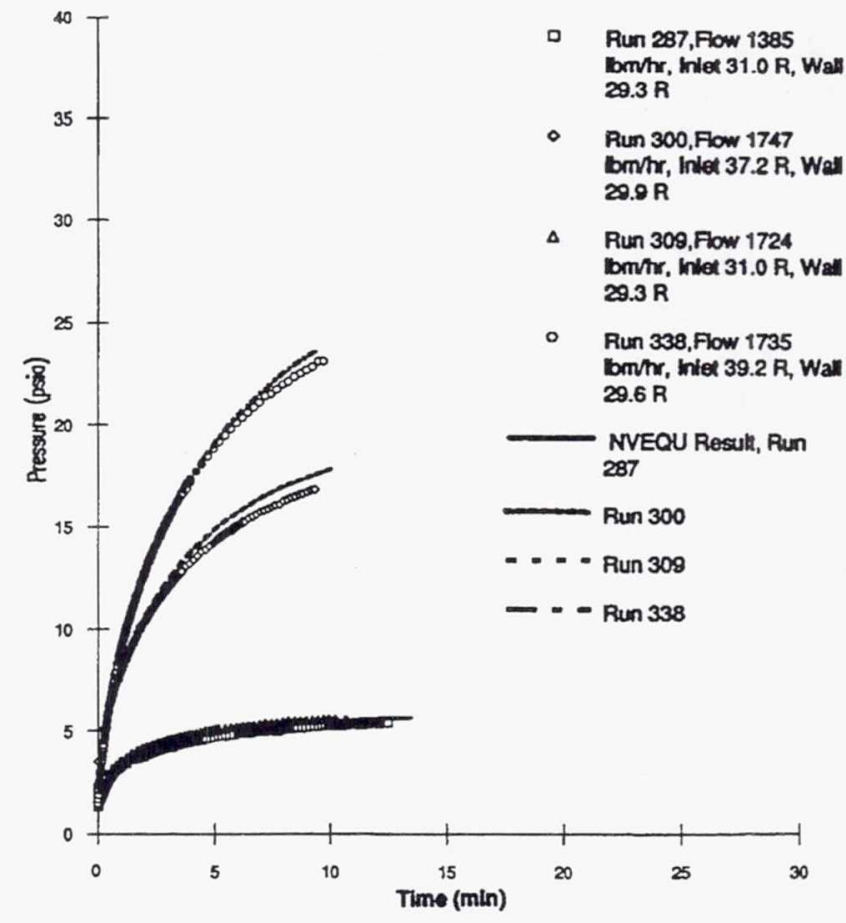

Figure 11.-Bottom orifice fill pressure history and analysis results runs with starting wall temperatures less than $100 \mathrm{R}$.

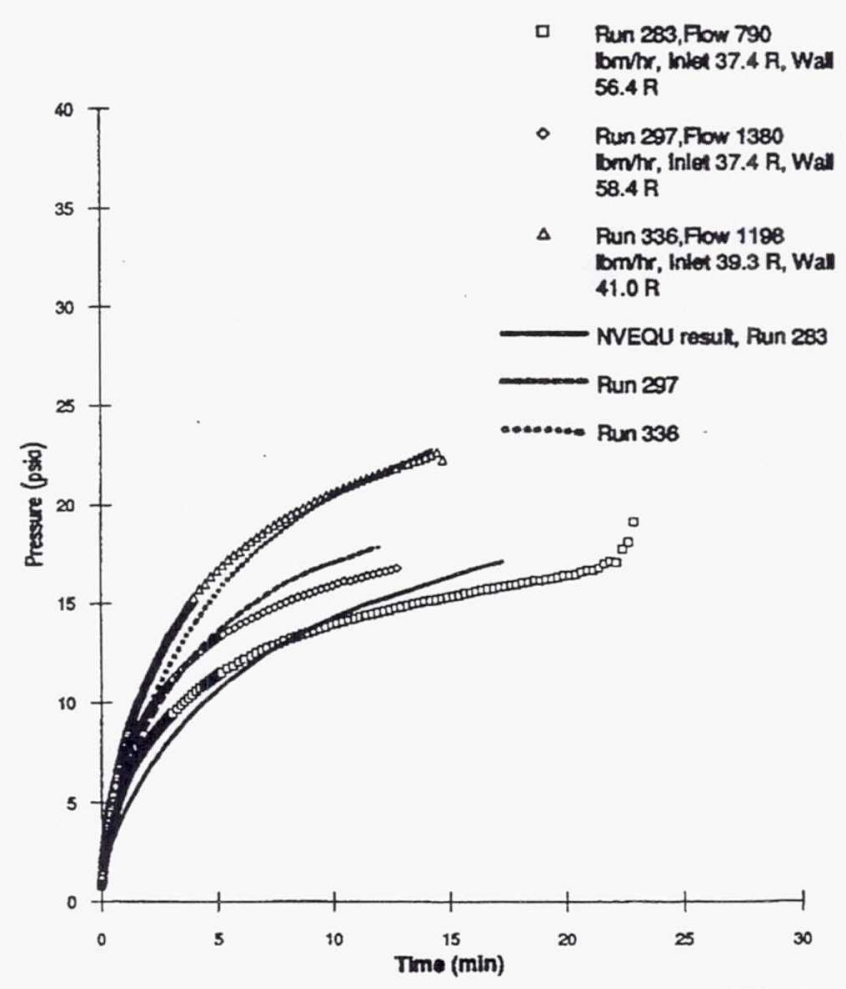

Figure 12.-Bottom orifice fill pressure history and analysis results runs with starting wall temperatures more than $40 \mathrm{R}$ but less than $100 \mathrm{R}$ 


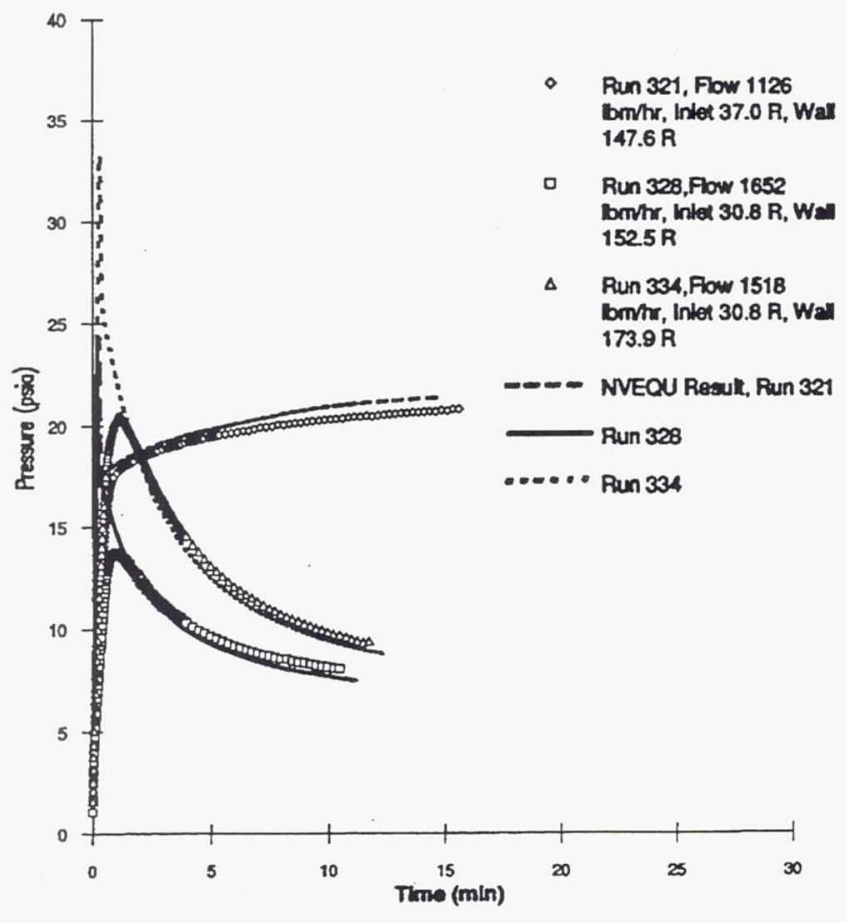

Figure 13.-Bottom orifice fill pressure history and analysis results runs with starting wall temperatures more than $100 \mathrm{R}$.

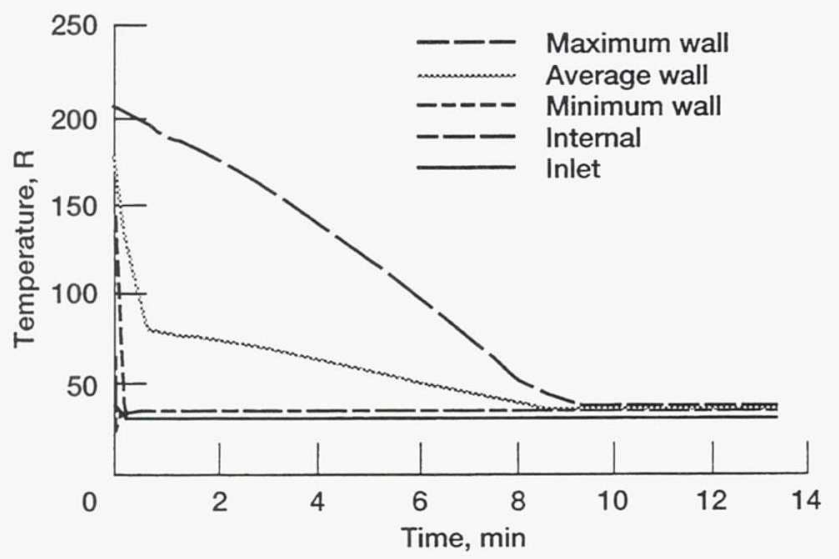

Figure 14.-Run 332 (spray bar, flow $1017 \mathrm{lbm} / \mathrm{hr}$, wall $178.8 \mathrm{R}$, inlet $31.3 \mathrm{R}$ ) temperature history.

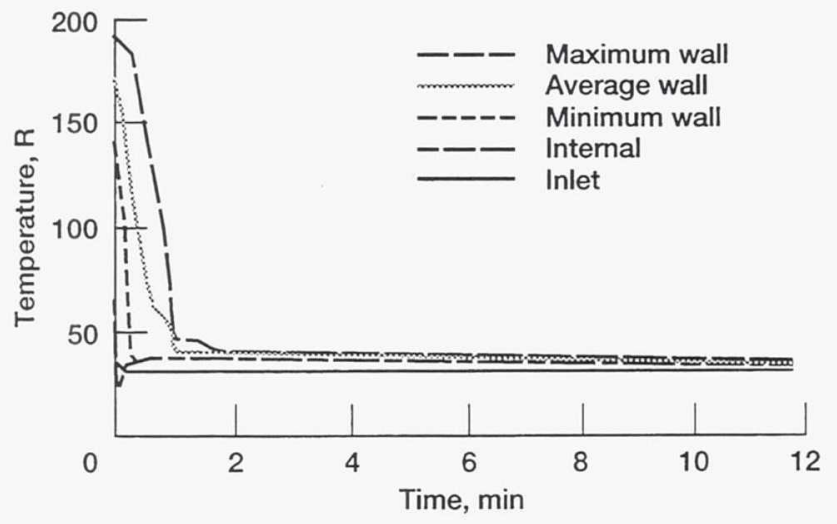

Figure 15.-Run 334 (bottom orfice, flow $1518 \mathrm{lbm} / \mathrm{hr}$, wall $173.9 \mathrm{R}$, inlet 30.8 ) temperature history.

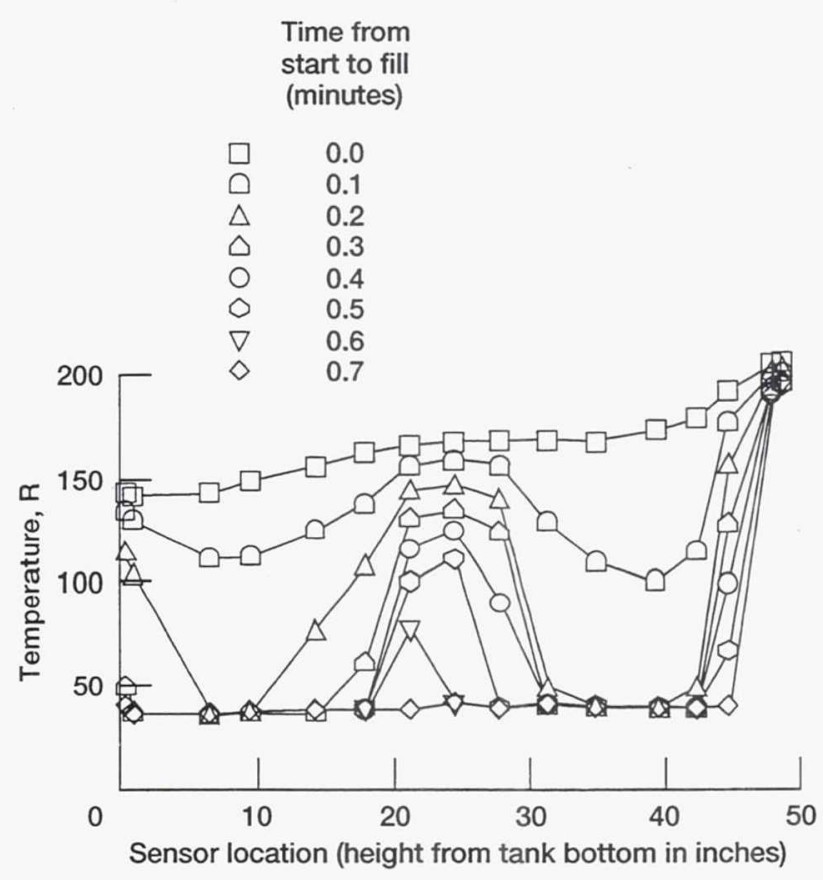

Figure 16.-Run 332 (spray bar, flow $1017 \mathrm{lbm} / \mathrm{hr}$, wall $178.8 \mathrm{R}$, inlet $31.3 \mathrm{R}$ ) initial wall cooling transients.

Time from start to fill (minutes)

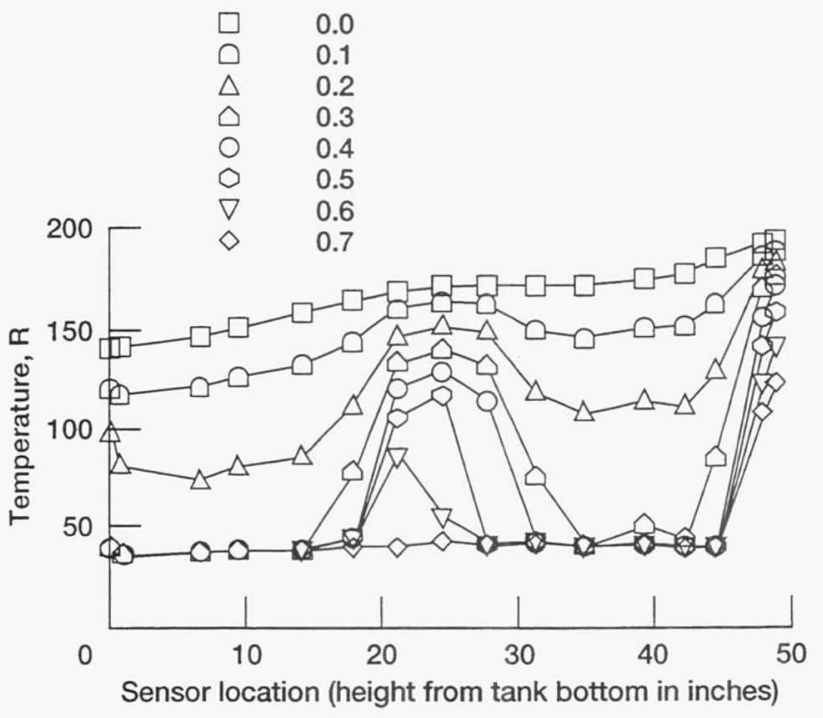

Figure 17.-Run 334 (bottom orfice, flow $1518 \mathrm{lbm} / \mathrm{hr}$, wall $173.9 \mathrm{R}$, inlet 30.8 ) initial wall cooling transients. 
Public reporting burden for this collection of information is estimated to average 1 hour per response, including the time for reviewing instructions, searching existing data sources, gathering and maintaining the data needed, and completing and reviewing the collection of information. Send comments regarding this burden estimate or any other aspect of this collection of information, including suggestions for reducing this burden, to Washington Headquarters Services, Directorate for Information Operations and Reports, 1215 Jefferson Davis Highway, Suite 1204, Arlington, VA 22202-4302, and to the Office of Management and Budget, Paperwork Reduction Project (0704-0188), Washington, DC 20503.

\begin{tabular}{|l|l|l|}
\hline 1. AGENCY USE ONLY (Leave blank) & $\begin{array}{c}\text { 2. REPORT DATE } \\
\text { June } 1993\end{array}$ & $\begin{array}{r}\text { 3. REPORT TYPE AND DATES COVERED } \\
\text { Technical Memorandum }\end{array}$ \\
\hline
\end{tabular}

4. TITLE AND SUBTITLE

5. FUNDING NUMBERS

Ground Testing for the No-Vent Fill of Cryogenic Tanks:

Results of Tests for a 71 Cubic Foot Tank

6. $A U T H O R(S)$

David J. Chato

7. PERFORMING ORGANIZATION NAME(S) AND ADDRESS(ES)

8. PERFORMING ORGANIZATION REPORT NUMBER

National Aeronautics and Space Administration

Lewis Research Center

Cleveland, Ohio 44135-3191

E-8030

9. SPONSORING/MONITORING AGENCY NAME(S) AND ADDRESS(ES)

10. SPONSORING/MONITORING AGENCY REPORT NUMBER

National Aeronautics and Space Administration

Washington, D.C. 20546-0001

NASA TM-106293

AIAA-93-1967

11. SUPPLEMENTARY NOTES

Prepared for the 29th Joint Propulsion Conference and Exhibit cosponsored by the AIAA, SAE, ASME, and ASEE, Monterey, California, June 28-30, 1993. Responsible person, David J. Chato, (216) 977-7488.

12a. DISTRIBUTION/AVAILABILITY STATEMENT

12b. DISTRIBUTION CODE

Unclassified -Unlimited

Subject Category 34

13. ABSTRACT (Maximum 200 words)

NASA Lewis Research has been investigating the no-vent fill method, since it is a promising approach to transfer liquid while handling the problems of low-g venting. This paper reports the results of a test series for filling a $71 \mathrm{ft}^{3}$ tank with liquid hydrogen without venting. 22 tests were conducted, 10 with a bottom orifice as the inlet and 12 with a spray bar. Parameters investigated included inlet saturation pressures of approximately 5, 15, and 25 psia, transfer pressures of 20,30 , and 45 psia, and various starting wall temperatures. Of the tests, only the one run at the highest wall temperature $(238 \mathrm{R})$ failed to fill the tank. Test results are compared to a thermodynamic equilibrium model. Overall model-data agreement was good except for the tendency of the model to overshoot during the initial wall cooldown of the higher starting wall temperature fills.

14. SUBJECT TERMS

Cryogenics: Fluid management; Reduced gravity 15. NUMBER OF PAGES 14

16. PRICE CODE $\mathrm{AO3}$

17. SECURTY CLASSIFICATION OF REPORT Unclassified

18. SECURITY CLASSIFICATION OF THIS PAGE

Unclassified
19. SECURITY CLASSIFICATION OF ABSTRACT Unclassified 